\title{
Acellularized porcine heart valve scaffolds for heart valve tissue engineering and the risk of cross-species transmission of porcine endogenous retrovirus
}
R. G. Leyh, MD, PhD
M. Wilhelmi, MD
T. Walles, MD ${ }^{\mathrm{a}}$
K. Kallenbach, $\mathrm{MD}^{\mathrm{a}}$
P. Rebe, $M D^{b}$
A. Oberbeck ${ }^{\text {b }}$
T. Herden ${ }^{\mathrm{b}}$
A. Haverich, MD, PhD
H. Mertsching, $P h D^{b}$

\footnotetext{
From the Division of Thoracic and Cardiovascular Surgery, Hannover Medical School, ${ }^{a}$ and LEBAO (Leibniz Research Laboratories for Biotechnology and Artificial Organs), Hannover, Germany. ${ }^{b}$

Received for publication Aug 1, 2002; revisions requested Aug 28, 2002; revisions received Dec 5, 2002; accepted for publication Dec 30, 2002.

Address for reprints: Rainer G. Leyh, MD, $\mathrm{PhD}$, Division of Thoracic and Cardiovascular Surgery, Hannover Medical School, Carl Neuberg St. 1, 30623 Hannover, Germany (E-mail: leyh@thg.mh-hannover.de).

J Thorac Cardiovasc Surg 2003;126:1000-4

Copyright $\odot 2003$ by The American Association for Thoracic Surgery

$0022-5223 / 2003 \$ 30.00+0$

doi:10.1016/S0022-5223(03)00353-2
}

Objective: Acellularized porcine heart valve scaffolds have been successfully used for heart valve tissue engineering, creating living functioning heart valve tissue. However, there is concern about the possibility of porcine endogenous retrovirus transmission. In this study we investigated whether acellularized porcine heart valve scaffold causes cross-species transmission of porcine endogenous retrovirus in a sheep model.

Methods: Acellularized porcine pulmonary valve conduits $(n=3)$ and in vitro autologous repopulated porcine pulmonary valve conduits $(n=5)$ were implanted into sheep in the pulmonary valve position. Surgery was carried out with cardiopulmonary bypass support. The animals were killed 6 months after the operation. Blood samples were collected regularly up to 6 months after the operation and tested for porcine endogenous retrovirus by means of polymerase chain reaction and reverse transcriptase-polymerase chain reaction. In addition, explanted tissue-engineered heart valves were tested for porcine endogenous retrovirus after 6 month in vivo.

Results: Porcine endogenous retrovirus DNA was detectable in acellularized porcine heart valve tissue. However, 6 months after implantation of in vitro and in vivo repopulated acellularized porcine heart valve scaffolds, no porcine endogenous retrovirus sequences were detectable in heart valve tissue and peripheral blood.

Conclusion: Acellularized porcine matrix scaffolds used for creation of tissueengineered heart valves do not transmit porcine endogenous retrovirus.

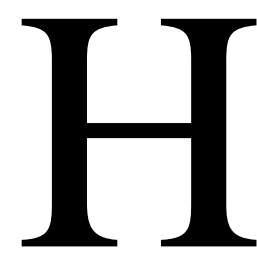

eart valve tissue engineering using scaffold matrix from allogeneic and xenogeneic biological sources resulted in functioning, living heart valves. ${ }^{1-3}$ Due to the shortage of allogeneic 3-dimensional heart valve scaffolds, acellularized xenogeneic scaffolds are an attractive alternative for heart valve tissue engineering. However, there is concern about the possibility of porcine endogenous retrovirus (PERV) transmission. ${ }^{4}$ This concern is supported by the findings from various groups who demonstrated PERV infection of human cell lines and primary human endothelial cells in vitro. ${ }^{5-7}$

The acellularization process for biological matrix scaffolds might not remove all native cells or cell debris. ${ }^{8}$ Moreover, we recently showed that after acellularization 
of porcine tissue, up to $2 \%$ of native DNA is still detectable within the matrix. ${ }^{9}$ These findings might indicate an increase risk for cross-species PERV transmission after implantation of acellularized porcine tissue. However, there are no data available indicating whether these cell remnants or DNA fragments are capable of PERV transmission.

To elucidate this problem, tissue-engineered heart valves based on acellularized porcine heart valve scaffolds were implanted into sheep for 6 months, after which the valvular tissue was assessed for PERV by means of polymerase chain reaction (PCR) and reverse transcription PCR (RTPCR). Furthermore, blood samples were drawn regularly for up to 6 months to detect PERV DNA/RNA.

\section{Methods}

\section{Acellularization of Valve Conduits}

Porcine pulmonary valve conduits $(n=8)$ were obtained from pigs (German landrace) ranging from 25 to $30 \mathrm{~kg}$ from the Tierzuchanstalt Mariensee. Hearts were obtained under sterile conditions, and pulmonary valve conduits were harvested with a thin ridge of subvalvular muscle tissue proximally and a short segment of the truncus pulmonalis distally. The valve conduits were stored at $4{ }^{\circ} \mathrm{C}$. Within 30 minutes, the valve conduits were placed in a bioreactor for acellularization. The conduits were placed in a bioreactor filled with $0.05 \%$ trypsin (Biochrom) and $0.02 \%$ ethylenediaminetetraacetic acid (EDTA; Biochrom) for 48 hours, followed by flushing with phosphate-buffered saline solution for 48 hours to remove all cell debris. All steps were conducted in an atmosphere of 5\% $\mathrm{CO}_{2}$ and $95 \%$ air at $37^{\circ} \mathrm{C}$ with the bioreactor rotating at a speed of $7 \mathrm{rpm}$, respectively, $21 \mathrm{rpm}$. Samples of the conduit were taken before and after treatment to document complete acellularization of the conduit.

\section{Cell Isolation and Culture}

The technique of cell isolation and cell culture have been described in detail elsewhere. ${ }^{1,10}$ For the generation of autologous cell culture, short segments of the right carotid artery were harvested from 5 lambs.

\section{Cell Seeding}

The acellularized porcine valve conduits $(n=5)$ were seeded first with myofibroblasts and coated with endothelial cells, resulting in a uniform cellular restitution of the pulmonary valve conduit surface. Three separate cycles of myofibroblast and endothelial cell seeding were performed. In each cycle $1 \times 10^{6}$ myofibroblasts or endothelial cells were seeded onto the xenogeneic pulmonary valve scaffold fixed into a bioreactor and cultured in static nutrient medium (Dulbecco's modified Eagle's medium, GIBCO, Karlsruhe, Germany) for 4 hours $\left(37^{\circ} \mathrm{C}, 5 \% \mathrm{CO}_{2}\right)$, followed by rotating of the bioreactor (12 hours, $0.1 \mathrm{rpm}$ ). Samples of the conduit were taken to document seeding of myofibroblast and endothelial cells.

\section{Pulmonary Valve Conduit Replacement}

Eighteen days after the initial cell seeding, the repopulated pulmonary valve conduits were implanted into the same 5 lambs from which the initial vessels harvested (age 10 to 12 weeks, weight 25 to $30 \mathrm{~kg}$ ), and the acellularized porcine heart valve scaffolds were implanted in the remaining 3 sheep. The technique has been described in detail elsewhere ${ }^{1}$; in brief, the heart was exposed by a left anterolateral thoracotomy, by means of femoral arterial and right atrial venous cannulation, and normothermic cardiopulmonary bypass was established. With the heart beating, the pulmonary artery was transected, all 3 native leaflets removed, and the valve conduits implanted. All animals received humane care in compliance with the "Guidelines for the Care and Use of Laboratory Animals" published by the National Institutes of Health (National Institutes of Health publication No. 85-23, revised 1985).

\section{Histology and Immunohistochemistry}

The acellularization treatment was documented by hematoxylineosin staining. Histological characterization was performed by means of standard hematoxylin-eosin and Movat-Pentachrom staining. Immunohistochemical staining for endothelial cell characterization was performed by use of the avidin-biotin-peroxidase technique (factor VIII-related antigen; primary antibody, von Willebrandt factor; clone 8/86, DAKO). For characterization of myocytes and fibroblasts, a double immunofluorescence technique with monoclonal antibodies against myocytes (monoclonal desmin antibody; clone C-18, Santa Cruz Biotechnology, Santa Cruz, Calif) and fibroblasts (polyclonal vimentin antibody; clone Vim H-84, Santa Cruz Biotechnology) were used.

\section{DNA and RNA Isolation from Tissue}

Porcine acellularized and explanted in vitro and in vivo repopulated heart valves were homogenized in a solution containing 4 $\mathrm{mol} / \mathrm{L}$ guanidine thiocyanate, $25 \mathrm{mmol} / \mathrm{L}$ sodium citrate, $0.5 \%$ Sarkosyl, and $0.1 \mathrm{~mol} / \mathrm{L} 2$-mercaptoethanol. Homogenate $(1 \mathrm{~mL})$ was mixed with $0.1 \mathrm{~mL} 2 \mathrm{~mol} / \mathrm{L}$ sodium acetate $(\mathrm{pH} 4)$. Watersaturated phenol $(1 \mathrm{~mL})$ was added after several inversions and thoroughly mixed, and $0.2 \mathrm{~mL}$ of $49: 1$ chloroform/isoamyl alcohol was added. Incubation occurred for 15 minutes at $4^{\circ} \mathrm{C}$. After centrifugation for 20 minutes at $10,000 \mathrm{~g}, 4^{\circ} \mathrm{C}$, the aqueous RNAcontaining phase was transferred in a second tube. The interphase and lower organic phase were used for precipitate DNA.

\section{DNA Precipitation}

Pure $(100 \%)$ ethanol $(0.3 \mathrm{~mL})$ was added per $1 \mathrm{~mL}$ of solution and incubated for 5 minutes at room temperature and centrifuged at $2000 \mathrm{~g}$ for 5 minutes at $4^{\circ} \mathrm{C}$. Protein containing supernatant was removed. The DNA pellet was washed twice in $0.1 \mathrm{~mol} / \mathrm{L}$ sodium citrate and resuspended in $75 \%$ ethanol, then incubated for 20 minutes at room temperature. The dried DNA pellet was dissolved in $8 \mathrm{mmol} / \mathrm{L} \mathrm{NaOH}$ and centrifuged at 12,000 $\mathrm{g}$ for 10 minutes. The supernatant was transferred to a new tube, DNA was quantified by reading the $A_{260}$, and 0.5 to $1 \mu \mathrm{g}$ was added to the PCR mix.

\section{RNA Precipitation}

RNA was precipitated by adding $1 \mathrm{~mL}$ of $100 \%$ isopropanol to the aqueous phase, incubated for 30 minutes at $-20^{\circ} \mathrm{C}$, then centrifuged $10,000 \mathrm{~g}$ for 10 minutes at $4^{\circ} \mathrm{C}$. RNA pellet was dissolved and precipitated by adding $0.3 \mathrm{~mL} 100 \%$ isopropanol. Incubation 
was for 30 minutes at $-20^{\circ} \mathrm{C}$. The pellet was washed with $75 \%$ ethanol. The supernatant was discarded and the pellet dried. RNA was dissolved in 100 to $200 \mu \mathrm{L}$ diethylpyrocarbonate-treated water, incubated for 15 minutes at $55^{\circ} \mathrm{C}$, and stored at $-70^{\circ} \mathrm{C}$. RNA was quantified by reading the $\mathrm{A}_{260}$ and $\mathrm{A}_{280} ; 1 \mu \mathrm{g}$ was used for RT-PCR.

\section{In Vitro Isolation of Peripheral Blood Monocytes from Whole Blood}

Ficoll-Paque gradient was prepared according to the manufacturer's instructions. Anticoagulant-treated blood was layered on the Ficoll-Paque solution and centrifuged at $400 \mathrm{~g}$ for 40 minutes at $20^{\circ} \mathrm{C}$. Differential migration during centrifugation results in the formation of layers containing different blood cell types. First, the upper layer of plasma was discarded. Then the lymphocyte layer was transferred to a clean centrifuge tube. Two washing steps followed, adding 3 volumes of balanced salt solution; centrifugation at $100 \mathrm{~g}$ for 10 minutes at $20^{\circ} \mathrm{C}$ followed that. The supernatant was removed, and the lymphocytes in pellets were homogenized in denaturing solution.

\section{Isolation of DNA and Total RNA of Peripheral Blood Monocytes and Tissue}

The cusps of 1 heart valve and Ficoll-Paque-isolated peripheral blood monocytes (PBMCs) were homogenized in a denaturing solution containing $4 \mathrm{~mol} / \mathrm{L}$ guanidine thiocyanate, $25 \mathrm{mmol} / \mathrm{L}$ sodium citrate, $0.5 \%$ N-lauroyl-sarcosine (Sarkosyl), and 0.1 $\mathrm{mol} / \mathrm{L}$ 2-mercaptoethanol. One milliliter of homogenate was mixed with $0.1 \mathrm{~mL}$ of $2 \mathrm{~mol} / \mathrm{L}$ sodium acetate $(\mathrm{pH} 4)$. After several inversions, $1 \mathrm{~mL}$ of water-saturated phenol was added and thoroughly mixed, and $0.2 \mathrm{~mL}$ of 49:1 chloroform/isoamyl alcohol was added. The suspension was incubated for 15 minutes at $4^{\circ} \mathrm{C}$. After centrifugation at $10,000 \mathrm{~g}$ for 20 minutes at $4^{\circ} \mathrm{C}$, the aqueous RNA-containing phase was transferred into a second tube. The interphase and lower organic phase were used to precipitate DNA.

\section{Purification of Viral RNA from Plasma}

For purification of viral RNA from human plasma, Qiagen QiAamp viral RNA Mini Kit (Qiagen GmbH, Hilden, Germany) was used. Viral RNA preparation was done according to the manufacturer's instructions.

\section{PERV-Specific PCR and RT-PCR}

These methods were performed according to the PERV pol-specific PCR/RT-PCR of Patience and colleagues ${ }^{5}$ and porcine-specific RT-PCR of Heneine and associates. ${ }^{11}$ For cDNA synthesis, 1 $\mu \mathrm{g}$ of total RNA and avian myeloblastosis virus-reverse transcriptase (Boehringer Mannheim, Germany) was used. PCR was done with $1 \mu \mathrm{g}$ of DNA. PCR products were separated on $2 \%$ agarose gel in an ethidium bromide-tris-acetate-EDTA buffer.

\section{Results}

All animals survived the operation and had an uneventful postoperative course.

\section{Histological and Immunohistological Evaluation}

The acellularization procedure resulted in a complete cell. Tissue-engineered valves showed a complete seeding of myofibroblasts and endothelial cells of the valve (seeding controls not transplanted) and conduit wall, evaluated by positive staining for von Willebrandt factor and vimentin desmin double immunofluorescence technique. Furthermore, the interstitium of the tissue-engineered pulmonary valve conduit showed a fibroblast and myocyte population similar to native ovine valve tissue. The Movat pentachrome stain showed amounts of stainable collagen, glycosaminoglycans, proteoglycans, and elastin similar to native ovine valve tissue.

\section{PERV Sequences in Heart Valve Tissue}

Two cusps of 1 heart valve and half of the surrounding annulus from 3 different porcine heart valves were used to isolate RNA and DNA. In acellularized porcine scaffolds PERV DNA was detectable. However, 6 months after implantation no PERV-specific sequences (PERV-specific PCR and RT-PCR) could be amplified in in vivo and in vitro repopulated heart valves (Figure 1).

\section{PERV Sequences in Sheep after Implantation}

Examination of peripheral blood monocytes and plasma of sheep by means of PERV-specific PCR (PERV-specific PCR and RT-PCR) revealed negative results up to 6 months after implantation of tissue-engineered heart valves based on acellularized porcine scaffolds (Figure 2).

\section{Discussion}

The search for an ideal heart valve substitute meeting the criteria outlined by Harken and Curtis ${ }^{12}$ led to the development of tissue-engineered heart valves; tissue engineering involves the reconstitution of viable autologous tissue on 3-dimensional scaffolds. ${ }^{13,14}$ Biodegradable polymer scaffolds as well as acellularized scaffold matrix from biological sources have been successfully used, creating functioning, living heart valve tissue. ${ }^{1-3,15-17}$ However, biological scaffolds have the advantages of preserved extracellular matrix proteins important for cellular attachment. ${ }^{18,19} \mathrm{We}$ recently showed that both biological scaffold sources (allogeneic and xenogeneic) used for heart valve tissue engineering will result in living heart valve tissue. ${ }^{1,2}$ The lack of acellularized autologous scaffold material favors acellularized xenogeneic scaffolds as a scaffold material for heart valve tissue engineering. However, little is known about the safety of acellularized porcine tissue in terms of crossspecies infection with PERV.

The safety of porcine tissue for xenotransplantation has been questioned recently by Patience and colleagues ${ }^{5}$ and Wilson and coworkers, ${ }^{6}$ who demonstrated that PERV is capable of infecting human cell lines in vitro. However, 


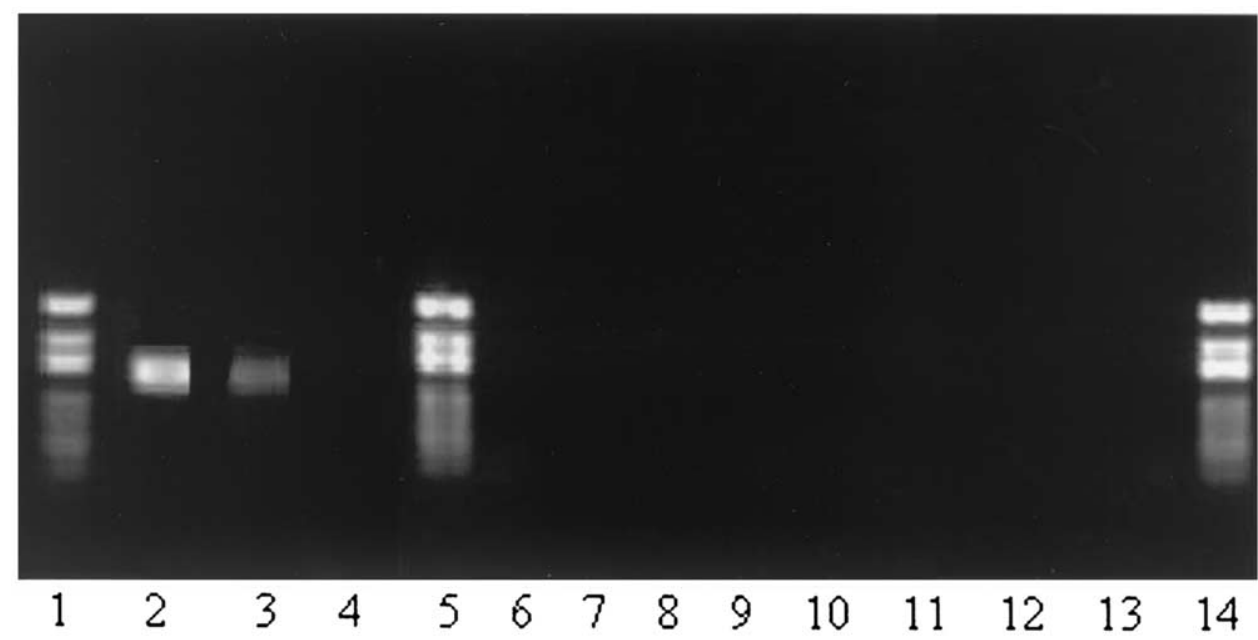

Figure 1. PERV sequences in in vivo and in vitro repopulated heart valves 6 months after implantation. Lane 1 , marker; lane 2, positive control (PCR of DNA from native porcine heart valve with porcine-specific primer); lane 3, PCR of DNA from acellularized porcine heart valve with porcine-specific primer; lane 4, negative control (PCR of DNA from native ovine heart valve with porcine-specific primer); lane 5, marker; lanes 6 to 8, PCR of DNA from sheep 6 months after implantation of acellularized porcine pulmonary valve scaffolds with PERV-specific primers; lanes 9 to 13, PCR of DNA from sheep 6 months after implantation of acellularized porcine pulmonary valve scaffolds repopulated in vitro with autologous ovine cells with PERV-specific primers, lane 14, marker.

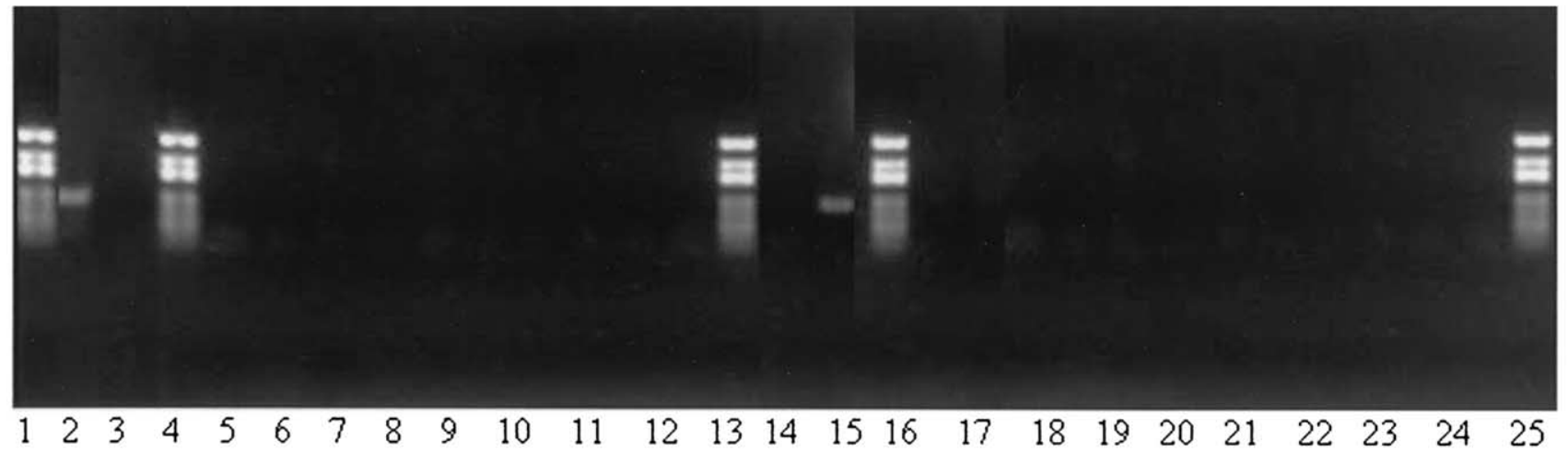

Figure 2. Plasma probes of sheep and PCR of DNA from PBMCs after implantation of tissue-engineered heart valves based on porcine acellularized heart valve scaffolds. Lane 1, marker; lane 2, positive control (PCR of porcine plasma with PERV-specific primers); lane 3, negative control (ovine plasma cells with PERV-specific primer); lane 4, marker; lanes 5 to 7, PCR of DNA from sheep plasma 6 months after implantation of acellularized porcine pulmonary valve scaffolds with PERV-specific primers; lanes 8 to 12, PCR of DNA from sheep plasma 6 months after implantation of acellularized porcine pulmonary valve scaffolds repopulated in vitro with autologous ovine cells with PERV-specific primers; lane 13, marker; lane 14, negative control (ovine PBMCs with PERV-specific primers); Iane 15, positive control (porcine PBMCs with PERV-specific primers); lane 16, marker; lanes 17 to 19, PBMCs of sheep 6 months after implantation of acellularized porcine pulmonary valve scaffolds with PERV-specific primers); lanes 20 to 24, PBMCs of sheep 6 months after implantation of acellularized porcine pulmonary valve scaffolds repopulated in vitro with autologous ovine cells with PERV-specific primers; lane 25, marker.

cross-species transmission of PERV to patients exposed to living pig tissue for a limited time could not be demonstrated. ${ }^{13,20}$ Moza and coworkers ${ }^{21}$ showed that glutaraldehydetreated porcine heart valves do not carry PERV DNA, and patients receiving porcine heart valves do not show any signs of PERV infection up to 3 years after implantation of glutaraldehyde treated porcine heart valves. Whether chemical acellularization of porcine tissue used for tissue engi- 
neering prevents PERV infection has not been delineated so far. In this context, however, Zeltinger and coworkers ${ }^{8}$ observed residual cell remnants after chemical acellularization of porcine heart valves. Furthermore, we demonstrated that after chemical acellularization of porcine tissue, up to $2 \%$ of native DNA is still detectable within the matrix. ${ }^{9}$ The possible clinical impact of this finding justified in vivo animal studies. According to our PCR and RT-PCR results, no fragments of PERV sequences were detected in tissueengineered heart valves after 6 months of implantation. Furthermore, we did not detect PERV RNA-DNA isolated from lymphocytes and plasma of sheep that underwent heart valve replacement with tissue-engineered heart valves based on acellularized porcine tissue. These results provide evidence that acellularized porcine heart valve scaffolds used for heart valve tissue engineering do not transmit PERV to sheep.

\section{Limitation of the Study}

Cross-species transmission of PERV has not been demonstrated in vivo. Although PCR and RT-PCR are sensitive tools for detecting PERV sequences, it could be argued that the failure to detect cross-species transmission of PERV in this study is a methodological problem. However, the implantation time of 6 months should be sufficient to detect any PERV infection with the methods used in this study. Other methods like electron microscopy, giving the capability to proof PERV transmission by direct proof of PERV virus, would have added further information.

In conclusion, we did not detect PERV transmission or infection in sheep after implantation of tissue-engineered heart valves based on acellularized porcine matrix scaffolds. The preliminary data from this study indicate that the chemical acellularization process with trypsin/EDTA is sufficient enough to prevent cross-species transmission of PERV in a sheep model. However, further studies are mandatory to draw the definite conclusion that the porcine matrix can be used as a scaffold for heart valve tissue engineering with no increased risk of cross-species transmission of PERV.

\section{References}

1. Steinhoff G, Stock U, Karim N, et al. Tissue engineering of pulmonary heart valves on allogenic acellular matrix conduits: in vivo restoration of valve tissue. Circulation. 2000;102:III50-5.
2. Leyh RG, Wilhelmi M, Herden T, et al. Artifiziell hergestellte Herzklappen mittels "tissue engineering" auf der Basis einer azellularisierten xenogenen Matrix: In-vivo Untersuchungen im Schafmodell. Chirurgisches Forum. 2002;31:469-71.

3. Dohmen PM, Ozaki S, Yperman J, Flameng W, Konertz W. Lack of calcification of tissue engineered heart valves in juvenile sheep. Semin Thorac Cardiovasc Surg. 2001;13:93-8.

4. Weiss RA. Transgenic pigs and virus adaption. Nature. 1988;391: 327-8.

5. Patience $C$, Takeuchi $Y$, Weiss RA. Infection of human cells by an endogenous retrovirus of pigs. Nat Med. 1997;3:282-6.

6. Wilson CA, Wong S, Muller J, Davidson CE, Rose TM, Burd P. Type $\mathrm{C}$ retrovirus released from porcine primary peripheral blood mononuclear cells infects human cells. $J$ Virol. 1998;72:3082-7.

7. Martin U, Winkler ME, Id M, et al. Productive infection of primary human endothelial cells by pig endogenous retrovirus (PERV). Xenotransplantation. 2000;7:138-42.

8. Zeltinger J, Landeen LK, Alexander HG, Kidd ID, Sibanda B. Development and characterisation of tissue-engineered aortic valves. Tissue Engineering. 2001;7:9-22.

9. Walles T, Ciubotaru S, Sorrentino S, et al. Cardiovascular tissue engineering: importance of scaffold matrix composition and scaffold thickness. JACC. 2002;39:198B.

10. Bader A, Schilling T, Teebken OE, et al. Tissue engineering of heart valves: human endothelial cell seeding on detergent acellularized porcine valves. Eur J Cardiothorac Surg. 1998;14:279-84.

11. Heneine W, Tibell A, Switzer WM, et al. No evidence of infection with porcine endogenous retrovirus in recipients of porcine islet-cell xenografts. Lancet. 1998;352:695-9.

12. Harken DE, Curtis LE. Heart surgery-legend and a long look. Am $J$ Cardiol. 1967;19:393-400.

13. Langer R, Vacanti JP. Tissue engineering. Science. 1993;260:920-6.

14. Niklason LE, Gao J, Abbott WM, et al. Functional arteries grown in vitro. Science. 1999;284:489-93.

15. Stock UA, Nagashima M, Khalil PN, et al. Tissue engineered valved conduits in the pulmonary circulation. $J$ Thorac Cardiovasc Surg. 2000;119:732-40.

16. Hoerstrup SP, Sodian R, Daebritz S, et al. Functional living trileaflet heart valves grown in vitro. Circulation. 2000;102:III44-9.

17. Shinoka T, Breuer C, Tanel R, et al. Tissue engineering heart valves: valve leaflet replacement in a lamb model. Ann Thorac Surg. 1995; 60:513-6.

18. Cheresh DA, Berliner SA, Vincente V, Ruggeri ZM. Recognition of distinct adhesive sites on fibrinogen by related integrins on platelets and endothelial cells. Cell. 1989;58:945-53.

19. Joshi P, Chung CY, Aukhil I, Erickson HP. Endothelial cells adhere to the RGD domain and the fibrinogen-like terminal knob of tenascin. J Cell Science. 1993;106:389-400.

20. Paradis K, Langford G, Long Z, et al. Search for cross-species transmission of porcine endogenous retrovirus in patients treated with living pig tissue. The XEN 111 Study Group. Science. 1999;285:123641.

21. Moza AK, Mertsching H, Herden T, Bader A, Haverich A. Heart valves from pigs and the porcine endogenous retrovirus: experimental and clinical data to assess the probability of porcine endogenous retrovirus infection in human subjects. J Thorac Cardiovasc Surg. 2001;121:697-701. 